\title{
Ischemic stroke and purpuric dermatitis as COVID-19-related complications in a peritoneal dialysis patient
}

\author{
Alberto de Lorenzo Alvarez ${ }^{1}$ (D) Ángela Revilla ${ }^{2} \cdot$ Teresa Corbalán $^{3} \cdot$ Ana Villar $^{4} \cdot$ Laura Espinel $^{1} \cdot$ Judith Martins $^{1}$. \\ Alfonso Cubas ${ }^{1}$
}

Received: 20 July 2020 / Accepted: 31 October 2020 / Published online: 17 November 2020

(c) Japanese Society of Nephrology 2020

\begin{abstract}
Patients on dialysis may have an elevated risk of severe coronavirus disease 2019 (COVID-19) and its complications due to their high prevalence of comorbidities. Here we describe the case of an 80-year-old male undergoing peritoneal dialysis with a moderate SARS-CoV-2 infection who developed a purpuric dermatitis and ischemic stroke after successful recovery from his bilateral pneumonia. Erythemato-papular lesions affecting trunk and lower limbs appeared 17 days after the onset of SARS-CoV-2 symptoms. These kind of lesions are an infrequent cutaneous manifestation of COVID-19. The pathology revealed a moderate purpuric dermatitis affecting superficial dermis and corticoesteroids were prescribed achieving complete resolution. Arterial thrombosis affecting cerebellar vermis emerged 30 days after the onset of COVID-19 symptoms. It occurred 5 days after withdrawal of antithrombotic prophylaxis that the patient received from his admission until 2 weeks after discharge. He completely recovered from his paresis and continued on his regular antiaggregation therapy. This is the first case report published of a patient with PD with such COVID-19-related complications. More experience is needed to determine the appropriate length of antithrombotic prophylaxis especially in high-risk individuals.
\end{abstract}

Keywords Coronavirus disease $19 \cdot$ Complications $\cdot$ Cardiovascular risk $\cdot$ Peritoneal dialysis $\cdot$ End-stage renal disease

\section{Introduction}

Since firsts cases in December 2019, acute respiratory syndrome coronavirus 2 (SARS-CoV-2) has killed over $1,000,000$ people all around the world. Patients on chronic dialysis are likely to be at increased risk of COVID-19 and its complications [1,2]. A matter of great interest is the wide spectrum of infection symptomatology and disease manifestation, ranging from asymptomatic carriers, life-threatening acute respiratory distress syndrome, multi-organ failure and death [3]. There are a number of emerging complications

Alberto de Lorenzo Alvarez

albertodelorenzoalvarez@gmail.com

1 Department of Nephrology, Hospital Universitario de Getafe, Carr. Madrid-Toledo, Km 12,500, Getafe, 28905 Madrid, Spain

2 Primary Care Center El Greco, Getafe, Madrid, Spain

3 Department of Radiology, Hospital Universitario de Getafe, Madrid, Spain

4 Department of Pathology, Hospital Universitario de Getafe, Madrid, Spain of the COVID-19 pandemic such as dermatologic impairment and ischemic stroke considered potentially lethal as the latter. Although the precise incidence of stroke in these patients is not known, some authors describe an incidence between 2.5 and 5\% [1-4]. Cutaneous manifestations in infected patients are beginning to emerge from around the world. Lesions may arise either before or after the signs and symptoms of COVID-19 [5-10]. Although they have been poorly described, may include erythematous maculo-papular [5], urticarial [5, 11], chickenpox-like [5, 12], purpuric periflexural [13], transient livedo reticularis, and acro-ischemic or chilblain-like lesions [14]. To date in literature, there are no cases of patients requiring maintenance hemodialysis (HD) or peritoneal dialysis (PD) with COVID-19-related ischemic stroke and/or cutaneous manifestations. Here, we describe our experience in the management of a maintenance PD patient with COVID-19 infection who developed both complications. 


\section{Case report}

Our patient is an 80-year-old male with end-stage renal disease (ESRD) secondary to ischemic nephropathy undergoing PD since 2015. He has hypertension, peripheral arterial disease stage IIa (Fontaine classification) and carotid endarterectomy in 2011 due to incidentally discovered asymptomatic stenosis. His usual treatment was folic acid, furosemide, calcium acetate/magnesium carbonate, atorvastatin, allopurinol and clopidogrel. The day before his admission he started with cough, yellowish sputum, short-of-breath and fever over $38 \mathrm{C}$, his chest X-ray at the emergency room showed moderate patchy infiltrates with peripheral distribution affecting both lungs (middle and lower fields). These findings were consistent with SARS-CoV-2 infection, but suspicion was confirmed by a positive real-time reverse transcriptase-polymerase chain reaction (rRT-PCR) test of pharyngeal swab. His laboratory tests (electrolytes, liver function, lactic acid, blood counts), were unremarkable except for an elevated D-dimer $(1.1 \mathrm{mg} / \mathrm{L}$, normal value $<0.5 \mathrm{mg} / \mathrm{L})$, high C-reactive protein $(15.9 \mathrm{mg} / \mathrm{L}$, normal value $<0.5 \mathrm{mg} / \mathrm{L})$, and a low platelet count $(134,000 / \mu \mathrm{L}$, normal value $150,000-450,000)$. The patient was admitted and treatment was initiated with hydroxychloroquine combined with lopinavir plus ritonavir as well as antithrombotic prophylaxis with low molecular weight heparin $(20 \mathrm{mg} /$ day subcutaneously). Twenty four hours after admission he had six episodes of watery stools that persisted until next day. Due to his partial respiratory insufficiency, the patient needed a nasal cannula with a $\mathrm{FiO} 2$ of $0.28(28 \%)$ for the first 5 days of hospitalization with no need for oxygen therapy thereafter. Systemic inflammatory reaction due to SARS-CoV-2 infection caused a situation of infradialysis, so a fourth peritoneal exchange was needed. In contrast, there were no problems in terms of ultrafiltration. He persisted febrile until day 7 of hospitalization progressing then successfully and being discharged on day 15 , maintaining antithrombotic prophylaxis for 2 weeks more. Two days after leaving the hospital, he was seen in Dermatology clinic for acute eruption of erythematopapular lesions affecting trunk and lower limbs. A punch biopsy of abdomen was performed and revealed the presence of moderate chronic and superficial purpuric dermatitis (shown in Fig. 1). Dermatologist put the diagnosis in relation to COVID-19 and prescribed $30 \mathrm{mg}$ of prednisone with a taper by $10 \mathrm{mg}$ decrements every week, achieving a complete recovery in day 10 of therapy. Five days after heparin withdrawal, he presented to our emergency department for evaluation of acute right lower limb paresis and unsteadiness of gait. The cranial CT discarded hemorrhage and a MRI demonstrated an acute ischemic stroke in

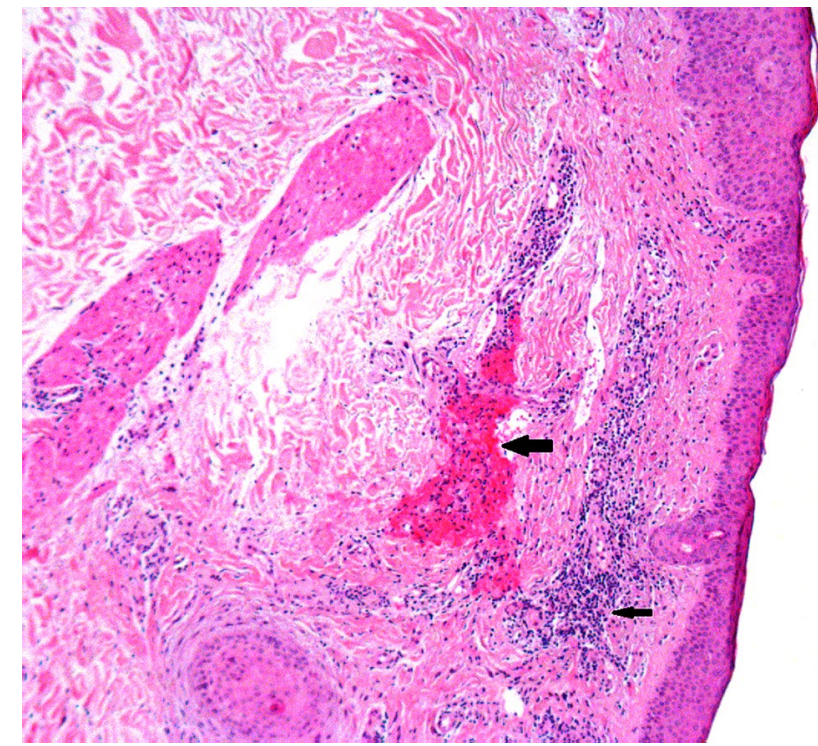

Fig. 1 Punch biopsy of abdomen. Microscopic examination with Hematoxylin and Eosin stain demonstrates histologic changes centered on superficial dermis represented by perivascular lymphocytic inflammation without vasculitis (fine arrow) and red blood cell extravasation (thick arrow). Focal and minimal changes are shown in epidermis (focal spongiosis, isolated parakeratosis, and basal vacuolar changes with minimal lymphocytic exocytosis)

cerebellar vermis (shown in Fig. 2). Further studies during this second hospitalization didn't objectify neither intra/ extracranial arterial stenosis nor emboligenous cardiopathy. The patient fully recovered movement ability and strength and was discharged. It is important to underline that laboratory tests at the time of skin lesions and stroke didn't show worsening of parameters, compared to those at the time of previous discharge.

\section{Discussion}

Coronavirus disease 2019 (COVID-19) infection is an ongoing pandemic, characterized by high morbidity and mortality that emerged from Wuhan (China) in December 2019. It is well known that certain preexisting medical conditions such as hypertension, diabetes, heart disease, and obesity lead to a decrease in resistance, being all of them risk factors making dialysis patients prone to severe SARS-CoV-2 infection and its complications. The infection rate and mortality in this group is much higher than in the general population; however, we have little information yet [15]. The complications described in this case report are of special interest because underline the higher risk of lethal complications of COVID19 dialysis patients. Those may be preceded by others less severe that should make us to be aware. 

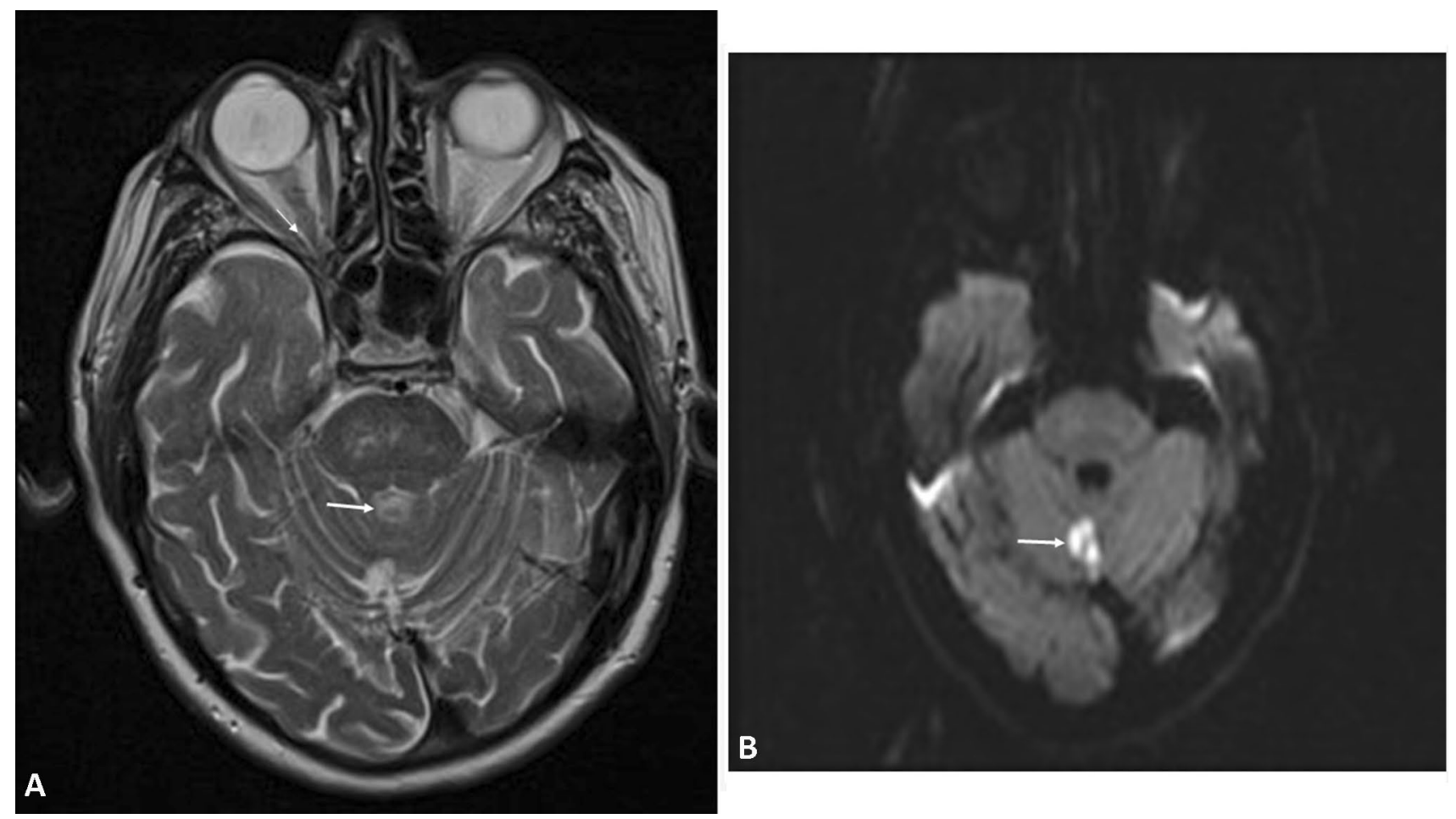

Fig. 2 MRI. a Axial T2-weighted image shows hyperintense lesion in cerebellar vermis demonstrating an ischemic stroke (arrow). b On ADC (apparent diffusion coefficients) map, the restriction of diffusion in the same location supports the acute onset of the stroke (arrow)

Recent literature reported multiple neurological symptoms in COVID-19 including anosmia, hypogeusia, seizures, and strokes. In a retrospective study from Wuhan with 214 hospitalized COVID-19 patients, $5.7 \%$ of the severe affected individuals developed cerebrovascular disease later in the course of illness [16]. In a study by $\mathrm{Li}$ et al. the incidence of stroke in COVID-19 patients was $5 \%$ with a median age of 71 years and an average time of onset of 12 days after SARS-CoV-2 infection diagnosis. These patients had more severe disease, hypertension, diabetes, and coronary artery disease [17]. In a recent research letter by Beyrouti et al., six patients with moderate to severe SARS-CoV-2 infection presented a stroke between day 0 and 24 after the onset of symptoms [18]. Lodigiani et al. published an incidence of $2.5 \%$ in a cohort of 388 COVID-19 hospitalized patients, despite the use of anticoagulant prophylaxis [19]. Our patient developed an ischemic stroke 30 days after the diagnosis of SARS-CoV-2 infection. The time of presentation of this event varies in the different case series published. In one of the patients reported by Beyrouti et al. stroke preceded COVID-19 symptoms by 2 days, nevertheless according to other authors stroke emerged later on the course of the infection ranging until 24 days after the onset of symptoms [15, $16,18]$. Stroke may be related to severity of the disease as most published cases had moderate to severe, severe or critical illness including our patient with a moderate impairment.
This is easy to understand as we know that SARS-CoV-2 infection is linked to a prothrombotic and proinflammatory state with an important release of cytokines, endothelial cells activation and coagulation leading to thrombosis [20]. Hypoxia may have an important role as well, but the exact pathophysiology behind these cerebrovascular accidents, especiallly in patients receiving antithrombotic prophylaxis, is still to be determined [3, 18, 21, 22]. Autopsy findings in lungs and kidneys suggest thrombotic microangiopathy as a possible mechanism of stroke [23-25]. At the time of this writing, only Solomon et al. have published neuropathological autopsy findings in COVID-19 patients, even though none of their 18 individuals developed a stroke [26].

Similar pathophysiological mechanisms may play a role in cutaneous involvement in SARS-CoV-2 infection, but there is not much information in this regard in the literature. Colmenero et al. have demonstrated the presence of SARS-CoV-2 in endothelial cells and epithelial cells of eccrine glands in 7 paediatric patients presenting with chilblains during the COVID-19 pandemic. Coronavirus particles were found in the cytoplasm of endothelial cells on electron microscopy [27]. Besides microvascular thrombosis, some authors have proposed immune dysregulation, vasculitis, or neoangiogenesis as cause of dermatologic impairment [28]. Reported prevalence of skin disease varies from $0.20 \%$ to $20 \%$ suggesting a potential 
underreporting of this complication $[12,29,30]$. This is of crucial importance since it may be the first (even the only) manifestation of the infection. The time of the onset of cutaneous involvement is not well determined in literature ranging from 0 to 21 days (when described) after the onset of the typical symptoms. In our patient skin manifestations emerged 17 days after the diagnosis of the infection. He was treated although some authors describe complete recovery without any therapy. Erythemato-papular lesions found in our patient are not the most common in COVID19 , with an incidence around $20 \%$ as reported in different studies. Saglietto et al. published an incidence of cutaneous impairment of $20.4 \%$ in a cohort of 88 COVID-19 hospitalized patients in Lecco (Italy), being eythematous rash the most frequent manifestation (15.9\%) [29]. In a preliminary review by Jia et al. with a pooled total of 997 patients, chilblain-like lesions were the most common $(40.1 \%)$ followed by maculopapular lesions $(23.1 \%)$, urticarial lesions (21.8\%), vesicular lesions (10.1\%), and livedoid/necrotic lesions (2.3\%) [31]. Seven patients from Wuhan (China) have been reported with acro-ischemia (toe cyanosis, skin bulla and gangrene), 4 of them with disseminated intravascular coagulation [32]. Recalcati et al. observed 14 cases including 11 children with an acral eruption of erythemato-violaceous papules and macules. Lesions were localized on the feet in eight cases, on the hands in four cases and on both sites in 2 [33]. Bouaziz et al. published a case series of 14 COVID-19 patients from France. Inflammatory lesions were reported in 7 patients, exanthema in 4 cases, chickenpox-like vesicles in 2 and cold urticaria in 1 patient. Vascular lesions were reported in 7 patients (violaceous macules, livedo, necrotic/nonnecrotic purpura, chilblain appearance, eruptive cherry angioma) [28].

Here we have described the case of two COVID-19-related complications not previously reported, neither alone nor together, in patients undergoing chronic dialysis (HD or PD). The temporal relationship with the COVID-19 pandemia, the rapid outbreak and clustering of unusual skin lesions and the slight increase of ischemic strokes according to the growing evidence published from other affected areas, strongly support the relationship. Considering that cutaneous manifestations may be the first or the only symptom of the infection, we should be aware of them to stablish early infection control and quarantine measures. Heparin is a key treatment of SARS-CoV-2, we know it saves lifes from early infection to hyperinflammation phase but it may help also to reduce mortality risk in post-infection period. We highlight the importance of define an appropriate length of antithrombotic prophylaxis after successful recovery from COVID-19 pneumonia in individuals with preexisting cardiovascular conditions, especially in dialysis patients.

\section{Compliance with ethical standards}

Conflict of interest The authors have declared that no conflict of interest exists.

Human and animal rights This article does not contain any studies with human participants or animals performed by any of the authors.

Informed consent Informed consent was obtained from all individual participants included in the study.

\section{References}

1. Hess DC, Eldahshan W, Rutkowski E. COVID-19-related stroke. Transl Stroke Res. 2020;11(3):322-5.

2. Aggarwal G, Lippi G, Michael HB. Cerebrovascular disease is associated with an increased disease severity in patients with coronavirus disease 2019 (COVID-19): a pooled analysis of published literature. Int J Stroke. 2020;15(4):385-9.

3. Avula A, Nalleballe K, Narula N, Sapozhnikov S, Dandu V, Toom $\mathrm{S}$, et al. COVID-19 presenting as stroke. Brain Behav Immun. 2020;87:115-9.

4. Oxley TJ, Mocco J, Majidi S, Kellner CP, Shoirah H, Singh IP, et al. Large-vessel stroke as a presenting feature of Covid-19 in the young. N Engl J Med. 2020;382(20):e60.

5. Recalcati S. Cutaneous manifestations in COVID-19: a first perspective. J Eur Acad Dermatol Venereol. 2020;34(5):e212-3.

6. Mahé A, Birckel E, Krieger S, Merklen C, Bottlaender L. A distinctive skin rash associated with coronavirus disease 2019? J Eur Acad Dermatol Venereol. 2020;34(6):e246-7.

7. Estébanez A, Pérez-Santiago L, Silva E, Guillen-Climent S, García-Vázquez A, Ramón MD. Cutaneous manifestations in COVID-19: a new contribution. J Eur Acad Dermatol Venereol. 2020;34(6):e250-1.

8. Su CJ, Lee CH. Viral exanthem in COVID-19, a clinical enigma with biological significance. J Eur Acad Dermatol Venereol. 2020;34(6):e251-2.

9. Mungmungpuntipantip R, Wiwanitkit V. COVID-19 and cutaneous manifestations. J Eur Acad Dermatol Venereol. 2020;34(6):e246.

10. Henry D, Ackerman M, Sancelme E, Finon A, Esteve E. Urticarial eruption in COVID-19 infection. J Eur Acad Dermatol Venereol. 2020;34(6):e244-5.

11. Fernandez-Nieto D, Ortega-Quijano D, Segurado-Miravalles G, Pindado-Ortega C, Prieto-Barrios M, Jimenez-Cauhe J. Comment on: Cutaneous manifestations in COVID-19: a first perspective. Safety concerns of clinical images and skin biopsies. J Eur Acad Dermatol Venereol. 2020;34(6):e252-e254.

12. Tammaro A, Adebanjo GAR, Parisella FR, Pezzuto A, Rello J. Cutaneous manifestations in COVID-19: the experiences of Barcelona and Rome. J Eur Acad Dermatol Venereol. 2020;34(7):e306-7.

13. Jimenez-Cauhe J, Ortega-Quijano D, Prieto-Barrios M, MorenoArrones OM, Fernandez-Nieto D. Reply to "COVID-19 can present with a rash and be mistaken for Dengue": Petechial rash in a patient with COVID-19 infection. J Am Acad Dermatol. 2020;83(2):e141-2.

14. Manalo IF, Smith MK, Cheeley J, Jacobs R. A dermatologic manifestation of COVID-19: transient livedo reticularis. J Am Acad Dermatol. 2020;83(2):700.

15. Yuan H, Guo E, Gao Z, Hu F, Lu L. Coronavirus disease 2019 in a hemodialysis patient. Blood Purif. 2020;27:1-4. 
16. Mao L, Jin H, Wang M, et al. Neurologic manifestations of hospitalized patients with coronavirus disease 2019 in Wuhan, China. JAMA Neurol. 2020;77(6):1-9.

17. Li Y, Wang M, Zhou Y, et al. Acute cerebrovascular disease following COVID-19: a single center, retrospective, observational study. Stroke Vasc Neurol. 2020:svn-2020-00043

18. Beyrouti R, Adams ME, Benjamin L, Cohen H, Farmer SF, Goh YY, et al. Characteristics of ischaemic stroke associated with COVID-19. J Neurol Neurosurg Psychiatry. 2020;jnnp-2020-323586.

19. Lodigiani C, Iapichino G, Carenzo L, Cecconi M, Ferrazzi P, Sebastian T, et al. Humanitas COVID-19 Task Force. Venous and arterial thromboembolic complications in COVID-19 patients admitted to an academic hospital in Milan, Italy. Thromb Res. 2020;191:9-14.

20. Tang N, Li D, Wang X, Sun Z. Abnormal coagulation parameters are associated with poor prognosis in patients with novel coronavirus pneumonia. J Thromb Haemost. 2020;18:844-7.

21. Tang N, Bai H, Chen X, et al. Anticoagulant treatment is associated with decreased mortality in severe COVID-19 patients with coagulopathy. J Thromb Haemost. 2020;18(5):1094-9.

22. Iba T, Levy JH, Warkentin TE, Thachil J, van der Poll T, Levi M. Diagnosis and management of sepsis-induced coagulopathy and disseminated intravascular coagulation. J Thromb Haemost. 2019;17(11):1989-94.

23. Fox SE, Akmatbekov A, Harbert JL, Li G, Brown JQ, Vander Heide RS. Pulmonary and cardiac pathology in African American patients with COVID-19: an autopsy series from New Orleans. Lancet Respir Med. 2020;8(7):681-6.

24. Barton LM, Duval EJ, Stroberg E, Ghosh S, Mukhopadhyay S. COVID-19 autopsies, Oklahoma, USA. Am J Clin Pathol. 2020;153(6):725-33.

25. Yao XH, Li TY, He ZC, Ping YF, Liu HW, Yu SC, et al. A pathological report of three COVID-19 cases by minimally invasive autopsies. Zhonghua Bing Li Xue Za Zhi. 2020;49(5):411-7.
26. Solomon IH, Normandin E, Bhattacharyya S, Mukerji SS, Keller K, Ali AS, et al. Neuropathological features of Covid-19. N Engl J Med. 2020. https://doi.org/10.1056/NEJMc2019373.

27. Colmenero I, Santonja C, Alonso-Riaño M, Noguera-Morel L, Hernández-Martín A, Andina D, et al. SARS-CoV-2 endothelial infection causes COVID-19 chilblains: histopathological, immunohistochemical and ultrastructural study of 7 paediatric cases. Br J Dermatol. 2020. https://doi.org/10.1111/bjd.19327.

28. Bouaziz JD, Duong T, Jachiet M, Velter C, Lestang P, Cassius C, et al. Vascular skin symptoms in COVID-19: a French observational study. J Eur Acad Dermatol Venereol. 2020. https://doi. org/10.1111/jdv.16544.

29. Saglietto A, D’Ascenzo F, Zoccai GB, De Ferrari GM. COVID-19 in Europe: the Italian lesson. Lancet. 2020;395(10230):1110-1.

30. Zheng Y, Lai W. Dermatology staff participate in fight against Covid-19 in China. J Eur Acad Dermatol Venereol. 2020;34(5):e210-1.

31. Jia JL, Kamceva M, Saieesh A, Rao SA, Linos E. Cutaneous manifestations of COVID-19: a preliminary review. J Am Acad Dermatol. 2020;S0190-9622(20):30924-5.

32. Zhang Y, Cao W, Xiao M, Li YJ, Yang Y, Zhao J, et al. Clinical and coagulation characteristics of 7 patients with critical COVID2019 pneumonia and acro-ischemia. Zhonghua Xue Ye Xue Za Zhi. 2020;41(4):302-7.

33. Recalcati S, Barbagallo T, Frasin LA, Prestinari F, Cogliardi A, Provero MC, et al. Acralcutaneouslesions in the time of COVID19. J Eur Acad Dermatol Venereol. 2020. https://doi.org/10.1111/ jdv. 16533 .

Publisher's Note Springer Nature remains neutral with regard to jurisdictional claims in published maps and institutional affiliations. 